\title{
ALLAH SEBAGAI PARSONDUK: PEREMPUAN PEMIMPIN DALAM KONTEKS GEREJA KRISTEN PROTESTAN SIMALUNGUN DAN MASYARAKAT SIMALUNGUN
}

\author{
Jusni H. Saragih ${ }^{1}$, Irene Umbu Lolo ${ }^{2}$, dan Minggus M. Pranoto ${ }^{3}$ \\ Gereja Kristen Protestan Simalungun ${ }^{1}$, Sekolah Tinggi Teologi Gereja Kristen Sumba ${ }^{2}$, \\ Sekolah Tinggi Theologia Abdiel ${ }^{3}$ \\ jusnisaragih@yahoo.com ${ }^{1}$,ireneumbulolo@gmail.com ${ }^{2}$, minggusminarto@gmail.com ${ }^{3}$
}

\begin{abstract}
This paper discusses a constructive theology by exploring the theme of Parsonduk in the context of Gereja Kristen Protestan Simalungun and its culture. The author uses feminist perspective to give a new meaning of Parsonduk. The original meaning of Parsonduk is a woman who feeds or spoonfeeds her family. The women in Simalungun's culture prepare the need of food for their families daily. Actually, this task is judged as the domestic work in the patriachal society. The task as Parsonduk is to serve the members of family such as husband and children. This paper recontructs theologically the meaning of Parsonduk by comparing the work fo God as the helper of Israel. The aim is to emphasize the important task of women at Simalungun's culture and to appreciate their role in the light of egaliterian perspective. Both men and women deserve to have the same opportunity to be leader in the church and society.
\end{abstract}

Keywords: collective consciousness; contructive theology; feminis; Myth;

Parsonduk; women leader

\section{Pendahuluan}

Saya adalah putri Simalungun yang lahir dari keluarga seorang penatua yang menjadi salah satu pemimpin jemaat di suatu desa. Sejak kecil saya bercita-cita menjadi pendeta supaya dapat melayani di Gereja Kristen Protestan Simalungun (GKPS) yang masuk dalam tradisi Gereja-Gereja Lutheran. Cita-cita itu datang karena sangat terkesan dan bersimpati kepada para pendeta yang datang melayani di jemaat kami. Mereka sering bersinggah di rumah kami dan banyak berdiskusi dengan bapak saya tentang kebenaran Firman Tuhan, ekonomi-pertanian, kemajuan infrastruktur, pendidikan, dan masa depan anak-anak desa kami. Saat waktunya tiba, seorang pendeta membantu saya untuk studi di sebuah sekolah tinggi teologi.

Bercita-cita menjadi pendeta bagi saya bukan hanya untuk melayani di jemaat, tetapi ada keinginan besar juga untuk dapat menduduki tempat strategis dalam struktur Pimpinan Pusat GKPS, yaitu sampai di posisi Sekretaris Jenderal dan Ephorus GKPS. 
Tujuannya adalah agar saya dapat memajukan pendidikan bagi anak-anak di lingkungan GKPS tempat saya melayani dan juga di tempat-tempat lainnya. Namun saya mengetahui keinginan tersebut sulit sekali untuk diwujudkan. Gereja tempat saya berada dilingkupi budaya patriarki yang sangat kuat. Kami mengenal adanya istilah yang dikenakan kepada perempuan di kebudayaan kami yang disebut parsonduk-penyendok atau menyuapi. Perempuan sejak lama distigmakan mempunyai pekerjaan sebagai parsonduk dalam lingkup domestik, yaitu melayani suami dan anak-anak di dalam rumah tangga, sedangkan laki-laki atau suami disebut sebagai pargotong. Sebagai suami ia diberi kehormatan untuk memakai topi adat yang secara simbolis mempunyai makna sebagai lambang kehormatan, pemegang keputusan, dan otoritas kepemimpinan tertinggi baik di rumah tangga, gereja, dan masyarakat.

Posisi perempuan yang diceritakan itu setidaknya diperkuat oleh salah satu mitos yang ada di Simalungun. Mitos yang saya ingat adalah tentang asal usul pohon enau atau aren. Mitos tersebut menceritakan tentang seorang putri bernama Boru Sibau yang rela mengorbankan tubuhnya untuk kepentingan orang-orang sekampungnya asalkan abangnya yang bernama Tarei Iluh dapat dilepaskan dari hukuman pasung oleh karena kalah bermain judi. Boru Sibau memanjat pohon yang tinggi, menangis, dan berseru-seru memohon abangnya dilepaskan dari pasung dan menjadikan dirinya sebagai tumbal. Seluruh bagian tubuh Boru Sibau mengalami perubahan: air matanya menjelma menjadi nira enau, rambutnya menjelma menjadi ijuk, dan anggota tubuhnya menjelma menjadi bagian dari pohon enau. Semuanya itu dapat dimanfaatkan orang-orang sesuai dengan permohonan Boru Sibou yang bersumpah menjadi apa saja asalkan abangnya itu dibebaskan. Mitos itu menjadi ingatan kolektif yang ada di alam bawah sadar masyarakat yang ingin mengatakan bahwa perempuan menempati posisi yang rela menjadi korban demi laki-laki.

Sejak menjadi vikaris saya memperhatikan bahwa ternyata GKPS juga tidak dapat lepas dari budaya Simalungun yang kuat dan dominan. Budaya patriarki terlihat jelas dalam kehidupan gereja kami yang mengatakan bahwa kepemimpinan yang strategis di gereja harus dipegang dan dikuasai oleh laki-laki. Di Sinode kami, penempatan pelayanan vikaris mempertimbangkan jenis kelamin. Vikaris laki-laki umumnya ditempatkan di kotakota dan kami vikaris perempuan di desa-desa dengan jemaat yang kecil. Pendeta perempuan umumnya ditempatkan di desa. Kalaupun ditempatkan di suatu kota maka akan ditempatkan di jemaat yang kecil atau menjadi pendeta yang diperbantukan.

Fakta menunjukkan bahwa baru ada satu perempuan pendeta yang menjabat sebagai praeses (ketua klasis) setelah 107 tahun Injil ada di Simalungun. Itupun satu dari 
tujuh orang praeses di GKPS. Bahkan sekarang ini saat distrik-distrik di GKPS berjumlah sembilan, perempuan yang menjadi praeses tetap hanya satu orang saja dan ditempatkan di desa.

Pegawai di Kantor Pusat GKPS ada 50 orang dan 19 orang di antaranya perempuan, namun tidak ada satu pun perempuan yang menduduki jabatan sebagai kepala departemen. Selama bertahun-tahun baru ada 3 orang perempuan pendeta yang pernah menjabat sebagai kepala departemen, itu pun mereka hanya bertugas selama 3 tahun saja. Padahal masa tugas setiap periodenya adalah 5 tahun. Dari 19 orang pegawai perempuan hanya 2 orang saja yang menjadi kepala bidang dan 5 orang kepala bagian, 13 orang sisanya menjadi staf. Benarlah teori piramida yang dikemukakan para ahli feminis soal kedudukan perempuan bahwa "semakin tinggi kedudukan dalam bidang pekerjaan tertentu, makin kecil perempuan berperan di dalamnya bahkan jarang sekali perempuan mencapai posisi puncak kepemimpinan"

Subordinasi terhadap perempuan dalam konteks GKPS dibentuk tidak saja dari mitos yang diceritakan itu, namun juga dari teologi yang dianut oleh GKPS. Sekalipun tidak ada aturan di dalam Tata Gereja GKPS yang melarang perempuan menjadi pemimpin utama, namun dalam realitasnya begitu sulit sekali bagi perempuan untuk mencapai posisi tinggi dalam kepemimpinan di gereja. Ini tidak untuk mengatakan bahwa perempuan begitu agresif dan bercita-cita untuk merebut tampuk kepemimpinan laki-laki yang ada, namun kesempatan untuk menuju ke sana tertutup dan terhambat oleh budaya patriarki yang sangat kuat.

\section{Allah adalah Laki-Laki, sebuah Mitos?}

Masyarakat atau suku bangsa hampir rata-rata mempunyai mitologinya masingmasing. Studi untuk menelusuri tentang adanya mitologi di suatu masyarakat bukanlah hal yang mudah. Meski gereja Kristen seringkali menentang mitos-mitos tertentu, namun khususnya mitos yang mendukung subordinasi perempuan nampaknya dipegang oleh gereja dengan teologi atau kepercayaan yang melatarbelakanginya. Mitos-mitos tersebut dan teologi Kristen menyatu lalu memperkuat budaya patriarkat yang ada di suatu

\footnotetext{
${ }^{1}$ Niken Savitri, "Feminist Legal Theory Dalam Teori Hukum," di dalam Perempuan dan Hukum: Menuju Hukum yang Berperspektif Kesetaraan dan Keadilan, edisi kedua ed. Sulistyowati Irianto. (Jakarta: Yayasan Obor Indonesia, 2006): 48.
} 
masyarakat. Tillich mengatakan bahwa kekristenan kait mengait dengan perkembangan religius, kultural, psikologis, dan sosiologis kemanusiaan ${ }^{2}$.

Kekristenan dalam sejarahnya selalu berhubungan dengan mitologi. Mitologi yang dimaksudkan adalah sebuah kumpulan mitos yang berbicara tentang suatu hal yang suci, agama atau tradisi kebudayaan dari sebuah kelompok orang-orang. Sedangkan mitos adalah kumpulan cerita yang disampaikan untuk menjelaskan mengenai asal usul alam, sejarah dan adat istiadat" ${ }^{\prime 3}$. Dalam perspektif psikologi, mitos merepresentasikan sebuah sumber penting mengenai kejiwaan manusia dan secara khusus mengenai aspek-aspek alam bawah sadar yang terdapat di dalam dirinya ${ }^{4}$. Kisah bahwa laki-laki lebih tinggi kedudukannya dari perempuan dan perempuan ditempatkan tersubordinasi terhadap lakilaki seringkali dibungkus dalam mitos-mitos yang ada sebagaimana terjadi di masyarakat Simalungun. Menurut Carl Jung, mitos-mitos itu kemudian tersimpan dalam the collective unconscious. ${ }^{5}$ Mitos-mitos tersebut menjadi simbol serta model untuk melanggengkan subordinasi perempuan kepada laki-laki.

Para teolog feminis mengkritik bahwa Yudaisme dan kekristenan adalah agamaagama yang dibungkus dengan mitos-mitos yang melanggengkan superioritas laki-laki di atas perempuan. Mitos, sebagaimana Mary Daly katakan, dalam kepercayaan Yudaisme dan Kristen "God is male and male is God". Dari manakah konsep itu muncul? Konsep itu ada dalam kitab suci kedua agama tersebut. Konsep itu terbentuk karena faktor sosial kultural yang bercampur dengan mitos-mitos pada masa saat itu.

Pada masa kehidupan leluhur-leluhur dan peristiwa eksodus, kira-kira pada 20001200 sZB, bangsa Israel dikenal sebagai masyarakat pengembara atau nomad. Di masa itu, berbagai fungsi dari pemburu, penggembala, dan pejuang-pejuang begitu penting untuk mempertahankan kehidupan ${ }^{7}$. Dalam keadaan masyarakat semacam itu maka status dan

\footnotetext{
${ }^{2}$ Paul Tillich, Systematic Theology, III. (Chicago: University of Chicago Press, 1963): 293-294.

${ }^{3}$ Bnd. dengan arti mitos yang oleh KBBI diartikan sebagai "cerita suatu bangsa tentang dewa dan pahlawan zaman dahulu, mengandung penafsiran tentang asal-usul semesta alam, manusia, dan bangsa tersebut mengandung arti mendalam yang diungkapkan dengan cara gaib.” http://kbbi.web.id/mitos diakses pada tanggal 17 Pebruari 2016.

${ }_{4}^{4}$ Janet Shibley Hyde, Half The Human Experience: The Psychology of Women, $3^{\text {rd }}$ ed. (Lexchussetington, Massachusetts: D.C. Heath and Company, 1985): 22.

5 Ibid., 22.

${ }^{6}$ Mary Daly, Beyond God the Father: Toward a Philosophy of Women's liberation (Boston: Beacon Press, 1973): 19.

${ }^{7}$ Hyde, Half The Human Experience, 33. Hyde menjelaskan ini sebagai berikut: "The collective unconscious . . . a storehouse of memory traces inherited from all previous generations, and from animal ancestors as well-what Jung calls one's "racial" memory. Jung, of course, does not mean that these memories are inherited in the sense of being passed by genes and chromosomes, but rather that they represent universal inherited tendencies for people to think and to perceives in certain ways. The collective 
posisi laki-laki menjadi lebih dominan dan unggul serta benar-benar dibedakan daripada perempuan ${ }^{8}$. Janet Shibley Hyde lebih lanjut mengatakan, "Given these conditions, it is not surprising that we find Old Testament women as the property or chattel of males, defined almost exclusively in procreative terms, their purpose being to produce children, preferably male children . . Thus, probably owing to cultural context, male dominance is a prominent theme in Judaism and the Old Testament"9.

Selanjutnya pada masa sesudah menyeberangi sungai Yordan dan menetap di wilayah tanah Kanaan atau Palestina kira-kira pada 1200-1000 SZB, kepercayaan Israel sering berhadapan dan bertarung dengan kepercayaan bangsa-bangsa Kanaan yang mempunyai sesembahan kepada ilah-ilah yang berhubungan dengan kesuburan. "The Canaanites believed that they could promote fertility by imitative magic; that is, by performing the sexual act in religious ceremonies, they re-enacted the relationship between Asherah (Astarte), the earth mother, and Baal, the sky king, and thus, they believed, stimulated the crops to fertility"10. Dalam konteks kebudayaan dan kepercayaan tersebut maka banyak kuil-kuil yang memuja ilah-ilah kesuburan dan mempraktikan prostitusi kultis baik para imam laki-laki maupun perempuannya. Namun demikian, "Women were highly involved, both as priestesses and as participants, because they symbolized the mother earth whose fertility was so valued"11. Selanjutnya reaksi perlawanan kepercayaan Israel terhadap kepercayaan Kanaan itu mau tidak mau memengaruhi cara pandang mereka terhadap natur perempuan.

Women were seen, in their sexuality, to be dangerous to pure Yahwism and, indeed, as agents of evil. The Old Testament expressions of the myth of feminine evil were fortified by the situation that Israel found upon settlement in Palestine. As Yahwism developed, it became more concerned with creation and the earth; but the creation myths that were added were attributed to Yahweh's male image and not to any female deity, as in other Near Eastern religions. ${ }^{12}$

Berdasarkan pengalaman kehidupan bangsa Israel dalam konteks masyarakat nomad dan agrikultural yang menekankan segi maskulinitas, muncul kecenderungan untuk menyebut

unconscious contains these universal symbols and interpretations that are shared by all people, ancient and modern. These symbols appear both in dreams and in myths."

${ }^{8}$ Janet Shibley Hyde, Half The Human Experience: The Psychology of Women, $3^{\text {rd }}$ ed. (Lexchussetington, Massachusetts: D.C. Heath and Company, 1985): 33.

${ }^{9}$ Ibid., 33.

${ }^{10}$ Ibid., 33 .

11 Ibid., 33.

${ }^{12}$ Ibid., 33 . 
aktivitas ilahi/ kepribadian Allah dalam metafora maskulinitas ${ }^{13}$. McGrath mengatakan, "One such analogy is that of a father" merupakan konstruksi masyarakat patriarkat yang menunjukkan kekuatan dan dominasi laki-laki. Tentu ini bukan konsep teologis Perjanjian Lama (PL) untuk mengatakan bahwa Allah berjenis kelamin laki-laki atau seperti dikatakan McGrath bahwa "Yet the statement that "a father in ancient Israel society is a suitable model for God" is not equivalent to saying that is male," or that "God is confined to the cultural parameters of ancient Israel" ${ }^{\prime 15}$. Konsep pembahasaan jenis gender Allah cenderung menjadi menonjol dalam masyarakat patriarki Israel, meskipun sebenarnya terdapat konsep-konsep lainnya yang menggambarkan segi feminitas Allah tetapi konsep-konsep ini kurang terekspos sama sekali dalam the collective unconscious di pikiran dan hati Israel. Sebaliknya konsep Allah yang maskulin ini lebih menjadi the collective unconscious yang terus dipelihara dan berakibat pada peninggian gender laki-laki. Jika Allah adalah laki-laki maka laki-lakilah yang mempunyai "jenis yang sama" dengan Allah yang kemudian dapat dan harus menjadi pemimpin. Inilah yang membentuk masyarakat patriarki yang kuat dan dominan, yang kemudian tidak saja dibatasi pada subordinasi perempuan kepada laki-laki tetapisebagaimana dikatakan Ruether-secara luas berarti juga bahwa " . . the whole structure of Father ruled society: aristocracy over serfs, masters over slaves, king over subjects, racial overlords over colonized people. Religions that reinforce hierarchical stratification use the Divine as the apex of this system of previlege and control"16.

Perjumpaan Israel dengan kepercayaan Kanaan, menimbulkan gambaran bahwa perempuan mempunyai "feminine evil" di dalam dirinya dan contoh yang utama mengenai ini dapat dilihat dalam mitos tentang kejatuhan manusia di dalam dosa (Kej. 3). Di kisah tersebut "Eve is the author of $\sin$ and the cause of man's expulsion from paradise"17. Walaupun demikian perlu diberi catatan bahwa persoalan itu bukan berarti semua citra perempuan sama sekali negatif di PL. Masih ada penghargaan yang tinggi terhadap posisi perempuan meski ditempatkan secara domestik yang peranan dan fungsinya umumnya sebagai Ibu dan istri. "Hebrew literature and mythology paid high tribute to the great mothers of the nation, such as Sarah,Rachel, and Myriam. The home was declared to be

\footnotetext{
${ }^{13}$ Alister E. McGrath, Christian Theology: An Introduction, $2^{\text {nd }}$ ed. (Cambridge, Massachusetts: Blackwell Publishers, 1997): 240.

${ }^{14}$ Ibid., 240.

${ }^{15}$ Ibid., 240.

${ }^{16}$ Rosemary Radford Ruether, Sexism and God-Talk: Toward a Feminist Theology (Boston: Beacon Press, 1993), 61.

${ }^{17}$ Hyde, Half The Human Experience, 33
} 
the women's sphere, but the home was so much productive than it is in our post-industrial age, for it was the center of commercial and mercantile life. Thus, the women's role was seen as vital to the health and strength of the nation"18.

The collective unsconcious dari PL menurut para teolog feminis semakin dikokohkan dengan pengajaran iman Kristen mengenai inkarnasi pribadi Allah kedua dari Allah Tritunggal di dalam diri Yesus Kristus yang mengambil wujud dan rupa seorang laki-laki. Para teolog feminis percaya bahwa gambaran Allah di dalam diri Yesus Kristus ini ikut mengokohkan gereja untuk memelihara the collective unsconcious. Kritikan ini bukan tanpa dasar, karena terbukti dalam sejarah gereja bahwa doktrin Kristologi yang dipegang gereja digunakan untuk menghalangi penahbisan dan kepemimpinan perempuan di gereja Katolik, Anglican, Lutheran dan Orthodok Timur. Ruether mengatakan,

"In Vatican and Roman Catholic episcopal statements Christology has been used as the keystone of the argument against women's ordination. It said that women, by their very nature, cannot 'image'Christ. Therefore they cannot be priests, since priests represent Christ. This argument has been echoed in other high church statements, Anglican, Lutheran and Eastern Orthodox". ${ }^{19}$

Apa yang dipercayai oleh gereja-gereja di atas itu tidak muncul di abad modern tetapi telah ada di awal sejarah gereja dan abad pertengahan yang pandangan teologinya didasari oleh para pemikir-pemikir klasik Kristen yang sangat berpengaruh. Seperti misalnya pemikiran dari Santo Augustinus yang dipengaruhi oleh filsafat dualisme Yunani, yang menggambarkan laki-laki dan perempuan sebagai dua hal yang saling bertentangan seperti antara jiwa dan tubuh, laki-laki dan perempuan, intelektual dan hawa nafsu, dominan dan subordinasi, superior dan inferior ${ }^{20}$. Ia juga menafsir I Korintus 11:7 yang hasil analisisnya mengatakan bahwa perempuan tidak memiliki gambar Allah di dalam dirinya, hanya laki-laki sajalah yang seutuhnya dan secara komplit memiliki gambar Allah $^{21}$. Aquinas mengikuti filsuf Aristoteles mengatakan bahwa perempuan sebagai

${ }^{18}$ Hyde, Half The Human Experience, 34

${ }^{19}$ Rosemary Radford Ruether, Introductions in Feminist Theology, diedit Mary Grey dan Lisa Isherwood dkk. (England: Sheffield Academic Press, 1998): 81. Ruether mengatakan bahwa diskriminasi terhadap perempuan ini dapat ditemukan di dalam "Vatican Declaration on the Questions of the Admission of Women to the Ministerial Priesthood (1976), sec. 27. Juga dapat dilihat dalam surat Pastoral Paus Yohanes II berjudul, "The Dignity and Vocation of Women" 31 September 1988. Dan juga dapat dibaca pada Surat Pastoral oleh Bishop-Bishop Katolik Amerika yang berjudul "One in Christ: A Pastoral Response to the Concerns of Women for Church and Society” (second draft), Origins, 5 April 1990, sec. 115,p. 730.

${ }^{20}$ Rosemary Radford Reuther, Women and Redemption: A Theological History, $2^{\text {nd }}$ ed. (Minneapolis: Fortress Press, 2012): 59.

${ }^{21}$ Augustine, The Literal Meaning of Genesis, in Ancient Christian Writers, vols. 41-42, J.H. Taylor,ed (New York: Newmann Press, 1982) 11.42 dan Agustine, The City of God, trans. Marcus Dods (New York: Western Library, 1950), 14.11. Dikutip oleh Radford Reuther, Women and Redemption, 59. 
misbegotten male dan setuju juga dengan gambaran Agustinus bahwa perempuan inferior, terutama pada bagian tubuh dan akal budinya lebih lemah. Akibatnya perempuan kurang dalam kemampuan akal budi dan moralnya serta dalam kemampuan kehendak dan kontrol dirinya $^{22}$. Luther mengatakan karena jatuh dalam dosa maka perempuan dihukum dengan cara kehilangan kesetaraannya dengan laki-laki dan menjadikan perempuan inferior dalam pikiran dan tubuhnya dibandingkan dengan apa yang dimiliki oleh laki-laki ${ }^{23}$.

Sedangkan Calvin menyebut perempuan sebagai ciptaan kedua (second in creation). Luther dan Calvin menolak perempuan menjadi pengkhotbah atau menjadi pejabat tertahbis, karena Alkitab memerintahkan perempuan tunduk kepada laki-laki. Keduanya menutup rapat-rapat kesempatan perempuan untuk mendapatkan otoritas atau menjadi pemimpin dalam pemerintahan gereja, tetapi mereka mendukung partisipasi penuh perempuan dalam jemaat dan mengizinkan perempuan melakukan pelayanan di ruang publik dalam situasi darurat. Luther memberikan garis pemisah yang tegas antara tanggung jawab untuk berkhotbah dan melayankan sakramen di dalam pelayanan publik yang hanya dapat dilakukan oleh laki-laki tertahbis. Calvin juga menegaskan bahwa jabatan publik (pengajar) tidak cocok untuk perempuan karena jabatan itu berhubungan dengan otoritas dan kepenilikan. Menurut hukum, perempuan harus tunduk kepada laki-laki dan berdiam $\operatorname{diri}^{24}$

Sikap Luther dan Calvin itu mempengaruhi teologi zending Rheinische MissionsGesellschaft (RMG) di GKPS. Struktur, tata gereja, dogma, liturgi, tradisi gereja induk dibawa dan langsung ditanam di lapangan misi serta dicap "Kristen". Tradisi itu bertemu dengan struktur masyarakat Simalungun yang feodalistik dan budaya Simalungun yang menekankan laki-laki sebagai pembawa marga. Partisipasi sepadan kaum perempuan dalam kepemimpinan di GKPS bukan hanya dihambat oleh rintangan teologis dan budaya, tetapi juga oleh alasan-alasan praktis seperti perempuan tertinggal dalam dunia pendidikan dan label sebagai yang lemah, emosional, dan kurang logis.

Mitos patriarkalisme di dalam kebudayaan Simalungun sudah ada jauh sebelum kekristenan tertanam di wilayah itu. GKPS memperkokoh mitos itu dengan praktik pelayanan gereja yang dimilikinya dan keyakinan teologisnya. Dari mana kita mesti mulai

\footnotetext{
${ }^{22}$ Ruether, Sexism and God-Talk, 96.

${ }^{23}$ Ibid., 97.

${ }^{24}$ Ruth A. Tucker \& Walter L. Liefield, Daughter of the Church (Grand Rapids: Zondervan Publishing House, 1987), 176. Bnd. Jane Douglass, Woman Freedom and Calvin (Philadelphia: Westminster Press, 1985): 46.
} 
merekonstruksi mitos-mitos yang telah bersatu padu itu dan sudah menancapkan diri secara kuat di dalam konteks pelayanan GKPS?

\section{Konstruksi Mitos dan Teologi dari Perspektif Teologi Feminisme}

Perspektif teologi feminisme menafsir realitas dari sudut pandang perempuan dengan cara mengangkat karakter, suara, dan peranan perempuan dalam semangat keadilan dan egalitarian, sebagaimana dikatakan oleh Robin C. McCall, "At the core, all feminist critics share the goal of providing interpretations that make room for everyone, regardless of jender, class, or race, to find a place in God's word and God's world"25. Perempuan dalam perspektif ini perlu membebaskan diri dari the collective unconscious yang diciptakan oleh laki-laki. Dalam kesadaran mereka perlu membentuk teologi dan praksis baru berdasarkan pada pengalaman sebagai perempuan yang merdeka dan tidak terjajah oleh ideologi laki-laki. Mereka perlu mengalami kebangkitan baru yang membawa kritik kepada kebudayaan dan kepercayaan lama melalui mentransformasi dan menciptakan ulang kembali makna baru yang menjadikan mereka dapat menghidupi hidup secara penuh dan otentik ${ }^{26}$. Para teolog feminis menyebut tugas ini sebagai memberi "new naming of self and world"27. Lebih lanjut dikatakan, "Naming women's experience thus becomes the model not only for personal liberation and growth, but for a feminist transformation of culture and religion" 28.

Oleh karena itu dalam konteks masyarakat Simalungun, perempuan mesti mempunyai keberanian untuk merekonstruksi mitos-mitos yang telah lama membelenggu. Mereka perlu, sebagaimana dikatakan Fiorenza, memiliki the hermeneutics of suspicion atau hermeneutik kecurigaan terhadap ideologi patriarki yang tersembunyi di dalam kebudayaan dan agama. Memakai istilah Fiorenza, di dalam konteks Simalungun perempuan perlu membuang tafsiran yang androsentris ${ }^{29}$, dengan melakukan strategi untuk merevisi mitos-mitos tersebut dan kemudian melakukan depatriarchalized dengan tujuan pembebasan perempuan. ${ }^{30}$

\footnotetext{
${ }^{25}$ Robin C. McCall, "Most Beautiful Among Women: Feminist/Womanist Contributions to Reading the Song of Songs," dalam Review and Exposito no. 105, 2008.

${ }^{26}$ Carol P. Christ and Judith Plaskow, ed. "Introduction: Woman Spirit," dalam Woman Spirit Rising: A Feminist Reader in Religion (San Fransisco: Harper Collins Publishers), 7.

${ }^{27}$ Christ and Plaskow, "Introduction," 7.

${ }^{28}$ Christ and Plaskow, "Introduction," 7.

${ }^{29}$ Elisabeth Schüssler Fiorenza, But She Said: Feminist Practices of Biblical Interpretation (Boston: Beacon Press, 1992), 23.

${ }^{30}$ Fiorenza, But She Said, 23.
} 
Dalam konstruksi teologi, parsonduk dalam konteks Simalungun perlu diberi makna yang baru dari sudut pandang pengalaman perempuan. Parsonduk harus diartikan sebagai pemberi kehidupan. Parsonduk membahas peranan perempuan yang begitu penting dalam mempersiapkan makanan bagi para anggota keluarga. Tanpa perempuan sebagai parsonduk maka kehidupan yang di mulai dari rumah dapat kacau balau dan tidak ada energi serta kekuatan bagi anggota keluarga. Tanpa perempuan sebagai parsonduk, kehidupan menjadi tidak sehat dan terancam punah. Kehidupan di mulai dari rumah dan bukan dari kantor atau masyarakat luas.

Istilah parsonduk adalah istilah yang di dalamnya mengandung tugas mulia. Perempuan sebagai parsonduk adalah ibu kehidupan yang memberikan kebaikannya untuk semuanya. Ia seperti bumi yang menyediakan segala sesuatu untuk makhluk hidup di dalamnya. Tanpa bumi yang menopang dan memberi makanan maka akan binasa dan hancurlah kehidupan di dalamnya. Peranan perempuan sebagai parsonduk adalah layaknya ibu kehidupan dari mana semua berasal. Sebagaimana Tuhan Allah menciptakan bumi untuk memberi makan semua makhluk, maka Ia menciptakan perempuan yang mempunyai posisi yang egaliter dengan laki-laki untuk melakukan tugas memberikan kasih, perawatan, dan pemeliharaannya kepada anggota-anggota keluarganya.

Dalam kebudayaan Simalungun, seringkali sebutan pargotong ${ }^{31}$ dimunculkan. Gotong adalah sejenis kain adat persegi empat yang digotongkan atau diikatkan di kepala laki-laki yang sudah menikah. Gotong dipakai untuk menunjukkan kewibawaan dan kehormatan. Istilah parbulang ${ }^{32}$ tidak mendapatkan penekanan penting dalam kebudayaan Simalungun. Padahal bulang juga dipakai oleh perempuan yang sudah menikah sebagai tanda atas kesiapannya berperan sebagai parsonduk. Istilah parbulang tersebut perlu diperbincangkan kembali dan diberi makna yang baru berkaitan dengan parsonduk sehingga dapat disejajarkan dengan pargotong. Parbulang adalah tanda tentang kesiapan seorang perempuan yang siap untuk melakukan pelayanan yang tulus dan memberkati yang lainnya. Pargotong dan parbulang adalah dua peran yang sejajar dan saling membutuhkan. Keharmonisan tercipta oleh karena persatuan keduanya ini. Sama seperti kesatuan antara langit dan bumi, tubuh dan jiwa, natur tidak tercipta dan tercipta, jasmani dan rohani, sekuler dan sakral dan seterusnya. Semuanya menunjukkan keharmonisan yang indah. memakainya.

${ }^{31}$ Gotong adalah kain adat yang diikatkan di kepala dan pargotong menunjukkan orang yang

${ }^{32}$ Bulang adalah kain adat yang dikenakan di kepala perempuan dan parbulang menunjukkan orang yang memakainya. 
Sedangkan mitos tentang Boru Sibou perlu diberi makna baru mengenai pergorbanan perempuan yang memberikan keselamatan bukan saja untuk abangnya Tarei Iluh, namun juga bagi banyak orang. Tanpa Boru Sibou masyarakat Simalungun tidak akan mendapatkan nira, gula, dan ijuknya dan sebagainya yang dapat diambil dari pohon itu. Pohon enau adalah pohon yang menghasilkan banyak hal dan menjadi tanaman yang serbaguna, tidak saja untuk manusia tetapi hewan juga. Pohon enau melambangkan tentang kemandirian dan jati diri perempuan yang tangguh dan mampu berkarya. Perempuan adalah sosok yang kuat dan mempunyai kelebihan-kelebihan yang berbeda dan setara dengan laki-laki. Sebagaimana pohon enau sebagai pohon yang memberikan kehidupan bagi masyarakat Simalungun, maka perempuan juga berpartisipasi dalam pengabdiannya untuk ikut serta memberikan daya hidup dan kehidupan dengan cara-caranya tertentu bagi masyarakat Simalungun.

\section{Problem Bahasa dan Misteri tentang Allah}

Konstruksi teologi dimulai dari bahasa mengenai Allah. Konsep Allah adalah lakilaki yang merupakan produk dari masyarakat patriarki. Esther Kuntjara dalam bukunya berjudul, "Jender, Bahasa, \& Kekuasaan" setuju dengan pendapat Dale Spender yang mengatakan "diskriminasi bahasa terhadap perempuan disebabkan karena bahasa adalah buatan laki-laki"33.

Gereja yang terbungkus dalam budaya patriarki, bahasa femininnya juga sering tidak dimunculkan. Jika membicarakan Allah maka bahasa yang dipakai adalah bahasa laki-laki. Lalu bagaimana merekonstruksi bahasa patriarki di dalam gereja saat menyebut nama Allah? Bahasa tentang Allah yang patriarki ini, seperti misalnya Allah sebagai Bapa tidak perlu dihapuskan. Moltmann memiliki alternatif bagi pencarian tersebut dengan mengatakan bahwa sebaiknya sebutan Allah sebagai Bapa itu dipahami sebagai "the father of the 'first-born' Son ${ }^{34}$, artinya Ia adalah Bapa yang mengandung dan melahirkan putraNya. Lebih lanjut Moltmann menjelaskan ini sebagai dikutip oleh Soskice "A father who both begets and gives birth to his son is no mere male father. He is a motherly father. He can no longer be defined as single-sexed and male, but become bisexual or transexual. He is the motherly father of his only-born Son, and the same time the fatherly Father of his

\footnotetext{
${ }^{33}$ Esther Kuntjara, Jender, Bahasa, dan kekuasaan, edisi revisi. (Jakarta: Libri, 2012): 6.

${ }^{34}$ Jurgen Moltmann, "The Motherly Father: Is Trinitarian Patripassianism Replacing Theological Patriarchalism,” dalam Metz J.B., Schillebeeckx, E., and Lefebure, M. eds., God as Father? (Edinburgh: T\&T Clark; New York: Seabury Press,1981): 51. Dikutip oleh Janet Martin Soskice, The Kindness of God: Metaphor, Jender, and Religious Language (Oxford: University Press, 2007), 82.
} 
only-born Son"35. Memang kelemahan dari pendapat Moltmann ini adalah tetap ada kecenderungan untuk memahami Allah sebagai Bapa dengan penekanan gender tertentu.

Teologi konstruksi tidak sekadar mengganti nama tetapi yang lebih penting adalah memunculkan bahasa yang feminin atau perempuan tentang Allah yang sering tidak dimunculkan di gereja. Jika sekadar mengganti sebutan Allah sebagai Ibu, lawan atau tandingan sebutan Allah sebagai Bapa, maka kita dapat terjatuh untuk melakukan ketidakadilan juga terhadap Alkitab yang begitu kompleks dalam membahasakan Allah; dan mungkin ini juga dapat menciptakan masyarakat matriarki yang menindas masyarakat patriarki. Jadi prinsipnya adalah bagaimana menggunakan bahasa yang seimbang untuk Allah dengan memperhatikan segi-segi "maskulinitas" dan "feminitas" Allah sebagaimana dikatakan oleh Alkitab dengan kesadaran bahwa semuanya itu adalah bahasa metafora yang mempunyai keterbatasannya untuk menyatakan realitas Allah yang sesungguhnya. Perlu konsep teologi sebagaimana dikatakan oleh McGrath bahwa "Neither male nor female sexuality is to be attributed to God. For sexuality is an attribute of the created order, which cannot be assumed to correspond directly to any such polarity within the creator God"36. Setuju dengan Sallie McFague, McGrath menambahkan, "We imagine God as both mother and father, but we realize how inadequate these and any other metaphors are to express the creative love of God... Nevertheless, we speak of this love in language that is familiar and dear to us, the language of mothers and fathers who give us life, from whose bodies we come, and upon whose care we depend"37.

Bagi para feminis masalahnya yaitu bahwa bahasa patriarki tentang Allah sebagai laki-laki telah mengabaikan aspek feminin Allah sebagaimana juga dinyatakan dalam Alkitab. Aspek feminin Allah terabaikan oleh gereja melalui bahasa patriarki tentunya menimbulkan masalah. Kassian membenarkan pendapat Russell yang menjelaskan tiga masalah terkait penggunaan bahasa tersebut dalam gereja yaitu pertama, bahasa seperti itu memperkuat stereotip inferioritas dan superioritas. Argumentasinya bahwa penggunaan bahasa dengan penyebutan laki-laki yaitu penggunaan generik laki-laki dan kata ganti lakilaki untuk merujuk pada Allah telah meniadakan partisipasi penuh perempuan dalam pengalaman kristiani. Dengan demikian memperkuat supremasi laki-laki dan merendahkan perempuan ke posisi “yang lainnya" 38 .

\footnotetext{
${ }^{35}$ Moltmann, "The Motherly Father," 52. Dikutip oleh Soskice, The Kindness of God, 82.

${ }^{36}$ McGrath, Christian Theology, 241.

${ }^{37}$ McGrath, Christian Theology, 241.

${ }^{38}$ Mary A. Kassian, The Feminist Gospel (Wheaton, Illionis: Crossway Books, 1992), 138-139.
} 
Masalah kedua yaitu perempuan diasingkan. Penggunaan bahasa tradisional dalam gereja tentang Allah sebagai laki-laki telah meminggirkan dan meniadakan perempuan. Bahasa tersebut mengakibatkan perempuan menjadi tidak penting, tidak dihargai, terluka, dan mengalami pengasingan dalam gereja ${ }^{39}$. Masalah ketiga yaitu bahasa patriarki itu membatasi konsep utuh mengenai diri dan karakter Allah karena Allah telah dikurangi, artinya hanya pada metafora laki-laki dan gambaran maskulin saja. Di dalam mengonseptualiasikan Allah terutama sebagai "Bapa" itu berarti banyak metafora alkitabiah yang kaya dan inklusif telah diabaikan. Bahasa patriarki tentang Allah membatasi dan mengganggu gambaran utuh mengenai siapa Allah sebenarnya yang melampaui keberadaan dan pemilahan gender manusia ${ }^{40}$. Dengan demikian, bahasa patriarki mengenai Allah sebagai laki-laki menjadi masalah utama bagi pembebasan perempuan dalam gereja. Bahasa itu mengakibatkan peminggiran perempuan dari kepemimpinan gereja. ${ }^{41}$ Bahasa ini telah turut menyumbang bagi tidak diakuinya identitas, potensi dan partisipasi perempuan dalam gereja.

Selain persoalan bahasa, harus disadari juga bahwa keberadaan Allah tidak dapat dijangkau secara sempurna oleh manusia yang memiliki keterbatasan termasuk terbatas dalam hal kosa kata untuk membahasakan tentang realitas keberadaan Allah. Persoalan ini yang juga ditegaskan oleh para teolog feminis. Menurut mereka penggunaan bahasa Allah laki-laki secara terus-menerus dan ekslusif menunjukkan kurangnya kesadaran mengenai misteri Allah. Tidak satupun nama atau gabungan nama sepadan untuk mengerti dan melukiskan tentang keberadaan Allah ${ }^{42}$.

Japinga menjelaskan penggunaan berbagai nama dan gambar mengenai Allah tidak hanya dapat diterima tetapi juga diperlukan untuk mencerminkan kepenuhan karakter dan aktivitas Allah. Kitab suci dan tradisi lebih banyak beragam di dalam bahasa mereka mengenai Allah daripada yang biasanya diakui oleh para penafsir ${ }^{43}$. Selanjutnya menurut Japinga, penjelasan tentang konsep ini nyata dalam pertanyaan Musa mengenai keberadaan Allah dan jawaban yang diberikan Allah kepadanya. Allah tidak memberi jawaban yang diharapkan Musa. Jawaban Allah kabur, tidak jelas dan tidak tegas. Allah hanya menyatakan "Aku adalah Aku". Terjemahan lain adalah, "Aku ada sesuai kehendak-Ku". Allah menolak untuk dimasukkan dalam satu kotak dan dengan tepat diberi terminologi

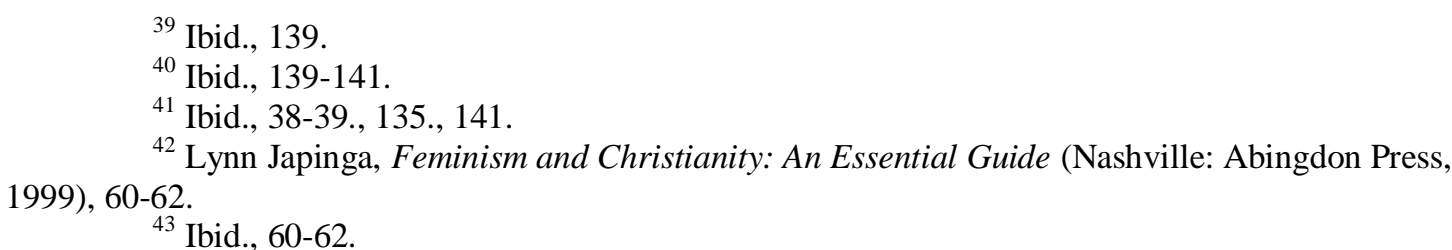


atau istilah yang agak mengada-ada. Aku adalah Aku mengingatkan Musa bahwa Allah adalah misterius. Allah tidak dapat sepenuhnya diketahui. Allah selalu ada beberapa langkah di depan melampaui spekulasi manusia. Ia selalu berada di luar jangkauan akal manusia $^{44}$.

Selanjutnya Japinga menjelaskan justru Allah yang misterius ini telah memilih untuk menolong dan berada bersama umat-Nya. Allah peduli pada mereka yang dikasihi. Allah sangat misterius dan menakjubkan sehingga pengetahuan seutuhnya mengenai Allah akan membuat manusia fana kagum tak habis-habisnya. Tokoh-tokoh Alkitab sangat terkagum-kagum ketika mereka mengalami hadirat Allah (Yes 6:1-8). Memang perjumpaan langsung seperti itu tampaknya jarang terjadi sekarang ini. Pengetahuan manusia mengenai Allah didapatkan melalui kitab suci, tradisi dan pengalaman iman, yang berarti bahwa pengetahuan itu dibatasi oleh kefanaan manusia dan dosa.

\section{Bahasa Feminitas untuk Allah}

Sebagaimana telah dikatakan di atas bahwa konstruksi teologi tidak sekadar mengganti nama atau atribut maskulin tentang Allah, namun sebaliknya memunculkan nama/ atribut yang feminin tentang Allah di dalam Alkitab terutama berkaitan dengan mitos-mitos yang telah direvisi. Parsonduk, parbulang, dan Boru Sibou berbicara tentang peranan para perempuan yang menyatakan pertolongan, kebaikan, pengorbanan, penghiburan, pelayanan kasih, pemberi kehidupan, kesejahteraan, dan keselamatan.

Alkitab ternyata banyak sekali menggambarkan aspek-aspek feminitas Allah. Kejadian 2:18 mengatakan Hawa sebagai penolong sepadan bagi Adam. Yang menarik, Allah juga disebut sebagai penolong ('ēzer) bagi umat-Nya (Kel. 18:4; Mzr 10:14; 118-7). Status dan peran penolong bukan dalam pengertian inferior atau subordinasi untuk orang yang memberikan pertolongan ${ }^{45}$. Allah sebagai penolong ini bisa dikatakan Allah sebagai Ibu-sebagaimana Hawa sebagai Ibu bagi keturunan manusia selanjutnya yang memberikan dukungan dan bantuan kepada umat-Nya. Allah sebagai Ibu yang tidak pernah lelah dan bosan menyatakan kasih kepada anak-anak-Nya.

Menurut Kitab Yesaya Allah menggambarkan diri-Nya sebagai perempuan [Ibu] yang menegur Israel dan tidak ingin membiarkan Israel mengambil jalan berdosa (Yes.

${ }^{44}$ Ibid.,61.

${ }^{45}$ Bill T. Arnold, Genesis. (United State of America: Cambridge University Press, 2009): 60. Posisi Hawa sebagai penolong menunjukan kesetaraan dirinya dengan Adam sehingga tidak ada hierarki antara keduanya. Lihat Miguel A. De La Torre, Belief A Theological Commentary on The Bible: Genesis (Louisville: Westminister John Knox Press, 2011): 32. 
42:14, bnd. Ul. 32:18; Yes. 46:3-4). Di dalam Yesaya 66:13 Allah menyatakan diri-Nya sebagai Ibu, "Sebab beginilah firman TUHAN: Sesungguhnya, Aku mengalirkan kepadanya keselamatan seperti sungai, dan kekayaan bangsa-bangsa seperti batang air yang membanjir; kamu akan menyusu, akan digendong, akan dibelai-belai di pangkuan. Seperti seseorang yang dihibur ibunya, demikianlah Aku ini akan menghibur kamu; kamu akan dihibur di Yerusalem”. Di Ayub 38:28-29, dikatakan bahwa pekerjaan Allah yang mahakuasa seperti Ibu yang melahirkan dan memberi kehidupan atas alam semesta ini, tidak saja kepada manusia tetapi juga binatang dan tumbuh-tumbuhan.

Bandingkan pandangan itu dengan teologinya Paulus di Kisah Para Rasul 17:26-28 yang menyatakan bahwa Allah memberikan nafas hidup dan Ia menaruh segala sesuatu yang hidup, yang bergerak, dan ada dalam diri-Nya. Apakah ini gambaran tentang rahim Allah yang melingkupi segala sesuatu yang ada di dalamnya? Menurut Mollenkott, dalam konteks Kisah Para Rasul 17:26-28 Paulus mempunyai pikiran dibenaknya tentang wombimage dan ini dihubungkan dalam kesadarannya dengan kata Ibrani rachum atau racham yang biasa diterjemahkan dengan compassion dan ini berkaitan dengan kata rahim ${ }^{46}$. Allah sebagai Ibu yang menginginkan manusia dan ciptaan lainnya yang ada di dalam rahim-Nya mendapat kebaikan, belaskasihan dan keselamatan-Nya. Di Yohanes 3:6, Pribadi ketiga Allah Trinitas disebutkan sebagai Pribadi yang memberi kelahiran baru atau melahirkan baru agar manusia dapat melihat dan masuk dalam Kerajaan Allah. Roh Kudus adalah Ibu kehidupan sumber segala kebaruan dan bersama dengan Allah Bapa dan Putra memberikan keselamatan bagi seluruh ciptaan. Di Lukas 15:8-10, Yesus Kristus menggambarkan kasih Allah yang menyelamatkan kepada pemungut cukai dan orang-orang berdosa melalui perumpamaan tentang dirham yang hilang. Allah seperti perempuan yang bersukacita karena menemukan kembali dirhamnya yang hilang, yaitu keselamatan bagi orang-orang berdosa.

Bandingkan perumpamaan tersebut dengan Injil Matius 23:37, ketika Yesus Kristus merindukan keselamatan untuk Yerusalem dan Ia mengumpamakan diri-Nya seperti induk ayam yang rindu mengumpulkan anak-anaknya di bawah sayapnya (bnd. Ul. 32:1-12, Kel. 19: Allah sebagai induk rajawali yang mendidik anak-anaknya ${ }^{47}$. Dalam Injil Yohanes 6:32, Tuhan Yesus menyatakan diri-Nya sebagai juru selamat dengan menyebut diri-Nya sebagai "roti hidup". Ini mengingatkan tentang Allah di PL yang menurunkan roti manna

\footnotetext{
${ }^{46}$ Virginia Ramey Mollenkott, The Divine Feminine: The Biblical Imagery of God as Female. (New York: Cross Road, 1987): 16.

${ }^{47}$ Gambaran ini juga mempunyai paralelnya dengan di Keluaran 19:4 dan mungkin juga di Ayub 39:27-30.
} 
untuk 40 tahun lamanya kepada bangsa Israel saat mereka ada di padang gurun. Pekerjaan membuat roti baik di Israel Kuno maupun abad pertama di Palestina dikerjakan oleh para perempuan $^{48}$. Tampaknya melalui sebutan roti hidup, Tuhan Yesus memposisikan diri-Nya seperti perempuan-perempuan pembuat roti yang menyediakan kebutuhan untuk anggotaanggota keluarganya. Dia sebagaimana Bapa-Nya adalah pembuat roti hidup atau roti surga yang memberikan berkat-berkat-Nya baik secara jasmani dan rohani.

Masih ada beberapa bahasa feminitas lainnya tentang Allah, misalnya di dalam Kitab Ruth 1:20-21 seperti sebutan Allah yang dalam Ibraninya Shaddai artinya Allah dengan buah dada ${ }^{49}$, atau Allah yang menyusui. Ada juga konsep mengenai kemuliaan Allah yang dihubungkan dengan konsep aspek feminitas Shekinah yang mulai dikembangkan dalam teologi Yudaisme abad 1 (bnd. Kel. 24:16-18; 33:7-11;40); konsep lainnya adalah tentang hikmat (hokmah), Roh kudus (ruach hakodesh); suara (bath-kol) dan lainnya ${ }^{50}$. Ini semua menunjukkan kekayaan metafora tentang feminitas Allah di Alkitab yang dapat menjadi bahan-bahan pendukung bagi rekonstruksi teologi yang dikerjakan dalam tulisan ini meski tidak secara langsung dapat dikaitkan dengan mitosmitos yang ada di Simalungun.

\section{Allah sebagai Parsonduk}

Berbagai pemaparan konstruksi-konstruksi yang sudah dijelaskan maka dalam konteks GKPS perlu dimunculkan konsep mengenai Allah sebagai parsonduk (berkaitan dengan parbulang dan kisah Boru Sibou). Allah sebagai parsonduk adalah Allah sebagai Ibu atau perempuan pemberi kehidupan dan tempat segala mahkluk bersandar kepada-Nya. Ia juga rela mengorbankan diri-Nya demi kehidupan dapat terselenggara dengan baik dan sejahtera. Metafora parsonduk untuk Allah menjadi metafora yang baru bagi umat GKPS yang dapat disejajarkan dengan metafora-metafora tentang Allah lainnya. Metafora Allah sebagai parsonduk menjadi metafora baru untuk menyatakan segi feminitas Allah, memperkokoh kejatidirian, dan kemandirian perempuan sebagai pemimpin, yang tanpa rendah diri dan malu-malu dapat terus mengasah serta menyatakan kepemimpinan mereka dalam konteks GKPS dan masyarakat Simalungun.

\footnotetext{
${ }^{48}$ Mollenkott, The Divine Feminine, 81-82.

49 Ibid., 57.

${ }^{50}$ Ibid., 36. Kata-kata yang disebutkan di atas berbentuk feminin.
} 


\section{Peneguhan tentang Perempuan Pemimpin di Alkitab}

Walaupun Alkitab umumnya bersifat androsentrik, ditulis, dan dikanonkan oleh laki-laki namun perlu ditekankan peranan penting perempuan baik dalam PL maupun Perjanjian Baru (PB) yang tidak saja dalam ranah domestik. Dalam tulisan ini tidak akan dikupas semua bagian-bagian Alkitab untuk membuktikan adanya perempuan-perempuan sebagai pemimpin. Beberapa contoh akan diberikan untuk mengokohkan kepemimpinan itu dan untuk membuktikan bahwa perempuan dapat menjadi pemimpin.

Di PL dapat dijumpai tokoh Ester yang menjadi tokoh penyelamat bangsanya yang akan dimusnahkan oleh Haman. Ester memimpin orang-orang Yahudi yang ada di pembuangan untuk berpuasa memohon keselamatan dan dengan berani mengadukan perkara bangsanya kepada Raja. Ini bukti kepemimpinan yang hebat dari Ester (Ester 4:16). Debora adalah seorang hakim yang ikut terlibat dalam pertempuran melawan Sisera (Hak. 4-5). Dalam pasal 4:14, nampaklah kepemimpinan yang menonjol dari Debora untuk memulai peperangan melawan Sisera.

Di dalam kitab Kidung Agung dapat dilihat bahwa peranan perempuan atau gadis Sulam dalam dialog dengan kekasihnya sangat menonjol. McCall mengatakan bahwa Kitab Kidung Agung menonjolkan peranan yang dominan dari si gadis Sulam dalam hubungannya dengan kekasihnya, meskipun peran dominan ini tidak dipahami untuk merendahkan kekasihnya itu. Lebih dari itu, McCall berani mengatakan bahwa terdapat kemungkinan bahwa penulis dari Kidung Agung adalah seorang perempuan dengan buktibukti secara internal dengan membandingkan dengan teks-teks lainnya yang mengatakan bahwa ada perempuan-perempuan yang terlibat dalam penulisan lagu (Kel. 15:21; Hak. 5; 2:8; 2 Sam 1:24; jer. 9:17-18; Yeh. 32:16; I Sam 2:1-10); dan juga bukti-bukti eksternal bahwa penulisan puisi yang erotis seperti Kidung Agung ini banyak ditulis juga oleh perempuan-perempuan lainnya di kebudayaan Mesopotamia dan Mesir pada waktu itu ${ }^{51}$. Bukankah hal ini menunjukkan bahwa perempuan dapat menjadi inisiator sekaligus pemimpin untuk memperjuangkan suatu ideologi yang pro perempuan di tengah-tengah cengkeraman masyarakat patriarki?

Perlu dijelaskan juga, bahwa meskipun Yesus Kristus (bergender laki-laki), namun dalam pelayanannya Ia sangat memberi tempat bagi perempuan dan menempatkan secara terhormat. Yesus adalah laki-laki yang memiliki hak-hak istimewa dalam masyarakat patriarki. Tetapi pelayanan-Nya menunjukkan, Ia begitu peduli dan berbelas kasihan

${ }^{51}$ Robin C McCall, "Most Beautiful Among Women: Feminist/ Womanist Contributions to Reading the Song of Songs". Review and Exposito, no. 105 (2008): 424. 
kepada para perempuan. Ia memutar balikkan sistem sosial dan menjadikan yang tertindas dari yang tertindas mengalami pembebasan seperti perempuan Samaria, perempuan SiroFenisia, janda miskin, perempuan yang mengalami pendarahan, pelacur, dan sebagainya. Perempuan merupakan bagian paling bawah dalalam hierarki sosial waktu itu, namun Yesus yang secara sosial memiliki hak istimewa justru menyelamatkan mereka ${ }^{52}$.

Yesus sebagai pembebas memanggil orang yang ditolak, ditindas, dan tercerai berai. Dia memprotes struktur sosial yang menindas dan kemampuan-Nya sebagai pembebas tidak terletak pada kelaki-lakian-Nya, tapi pada kenyataan bahwa Ia telah meninggalkan sistem dominasi dan berusaha untuk mewujudkan kemanusiaan yang baru dan pemberdayaan bagi yang lainnya ${ }^{53}$.

Secara teologis, kelaki-lakian Yesus tidak memiliki arti utama dalam masyarakat patriarki yang mengistimewakan hak laki-laki, tapi Ia justru menantang sistem patriarki tersebut. Ia memanifestasikan "kenosis patriarki", proklamasi kemanusiaan baru melalui gaya hidup yang membuang hierarki kasta istimewa dan berbicara atas nama kerendahan dan kesetaraan ${ }^{54}$.

Di dalam dan melalui Yesus Kristus, perempuan ditebus. Oleh karenanya kristologi tidak boleh dibuat menjadi pembela gender maskulin. Yesus Kristus membangun kemanusiaan baru melalui kesatuan antara perempuan dan laki-laki. Yesus Kristus sebagai penebus dan Firman yang membebaskan. Komunitas Kristen diminta meneruskan identitas pelayanan Yesus Kristus ini. ${ }^{55}$

Konsep kesetaraan dinyatakan dalam berbagai ajaran Yesus seperti Basilea Allah yang inklusif yang sudah, sedang, dan akan hadir bagi semua orang. Para perempuan, orang miskin, tertindas, sakit, pemungut cukai, orang berdosa, pelacur, dikasihi-Nya. Visi basilea-Nya memulihkan kemanusiaan dan kehidupan orang banyak secara utuh. Ia membuat orang pulih, sehat, tahir, kuat dan sebagainya ${ }^{56}$. Bagi Yesus Kristus, Allah adalah Allah Sofia yang menyatakan kebaikan yang penuh rahmat dalam menciptakan dunia ini. Sofia hadir dalam diri seorang perempuan. Ia dipanggil saudari, istri, ibu, kekasih, dan guru. Sofia Allah di dalam diri Yesus Kristus menghendaki keutuhan dan kemanusiaan dari

\footnotetext{
${ }^{52}$ Rosemary Radford Ruether, Sexism and God-Talk: Toward a Feminist Theology. (Boston: Beacon Press, 1993): 137.

${ }^{53}$ Ibid., 137.

${ }^{54}$ Ibid., 137.

${ }^{55}$ Ibid., 138.

${ }^{56}$ Elisabeth Schüssler Fiorenza, Untuk Mengenang Perempuan Itu: Rekonstruksi Feminis tentang
} Asal Usul Kekristenan. (Jakarta: BPK Gunung Mulia, 1997): 167-177. 
setiap orang, oleh karenanya Ia memampukan semua orang dalam kemuridan yang sederajat. $^{57}$

Jika melihat perkembangan gereja mula-mula, dapat ditemukan bahwa para perempuan berperan sebagai pemimpin, rasul, nabi, guru, pengajar, dan misionaris. Kotakota yang banyak dipengaruhi kebudayaan Helenis dan Romawi, kaum perempuannya berperan sebagai pejabat pengadilan dan pemerintahan, serta sebagai imam dan staf keagamaan $^{58}$. Kisah Para Rasul menceritakan peran pemimpin perempuan seperti Maria ibu Yohanes Markus, Priskila, dan Lidia. Mereka umumnya memiliki status ekonomi yang mapan, juga mualaf Romawi, serta memberikan rumahnya sebagai tempat jemaat rumah. Lidia misalnya adalah perempuan karir yang menjadi pendiri jemaat Filipi dan rekan sekerja Paulus (Kis. 16:15). Kendati pun sangat sedikit peran perempuan yang diangkat dalam Kisah Para Rasul, namun tokoh-tokoh itu merepresentasikan adanya kepemimpinan perempuan dalam jemaat mula-mula. Roma 16 menyebutkan banyak peran kepemimpinan perempuan misalnya Febe, seorang Kristen kafir yang menjadi pemimpin di jemaat Kengkrea (Rm 16: 1-2) dan diberikan tiga gelar yaitu saudari, diakonos, dan prostatis. Istilah diakonos dalam teks ini tidak menunjukkan terminologi feminis, walaupun Febe adalah seorang perempuan. Memang masih ditemukan pro kontra di antara para ahli PB apakah gelar tersebut menunjukkan jabatan yang khusus dalam jemaat atau menyatakan pelayanan secara umum, mengingat kata Yunani yang digunakan adalah kata bendadiaken, dalam bentuk maskulin-, mungkin juga bahwa gelar itu menunjukkan jabatan dalam jemaat ${ }^{59}$.

Gelar tersebut juga dimodifikasi dengan istilah synergos (rekan sekerja), yang menyatakan peran serta Febe dalam pekabaran Injil. Kemudian juga ada Priskila dan Akwila suaminya yang punya peranan besar membantu misi pelayanan Rasul Paulus (Kis. 18:1; 1 Kor. 16:19 dan 2 Tim. 4:19). Para ahli PB umumnya mengakui bahwa penyebutan nama Priskila lebih dulu dari pada nama Akwila suaminya itu menunjukkan bahwa peranan Priskila yang lebih menonjol dalam pekabaran Injil dari pada suaminya-yang menjalankan usaha sebagai tukang kemah—(Kis. 18:3). Dugaan kuat bahwa Paulus sudah mengakui kemampuan Priskila sehingga mempercayakan pekabaran Injil kepadanya di Efesus. Ia juga menjadi pendiri dan menjadi pemimpin jemaat di jemaat rumah, bahkan Apolos belajar juga dari Priskila. Para teolog feminis menekankan peranan penting Priskila

\footnotetext{
${ }^{57}$ Ibid., 182-186.

${ }^{58}$ Ibid., 320-321.

${ }^{59}$ Van den End, Tafsiran Alkitab Surat Roma. (Jakarta: BPK Gunung Mulia, 1995): 691-692.
} 
dan Akwila dalam pelayanan misi di jemaat mula-mula dalam hal mengajar, kesetiaan dalam pekabaran Injil, kesediaan menjadikan rumahnya sebagai tempat ibadah dan lainlain. Beberapa tokoh tersebut hanyalah sebagai representasi perempuan pemimpin dalam jemaat mula-mula.

Ternyata di tengah-tengah penulisan Alkitab yang androsentris, masih ditemukan juga peran perempuan menjadi pemimpin. Perempuan bukan hanya sebagai pendukung tambahan tapi memiliki peran penting dan menikmati tempat strategis dalam persekutuan Kristen. Lebih jauh lagi Torjesen menyatakan, "The New Testament writers generally mentioned woman leaders only as a passing fact while hurrying on to address more pressing concerns ... where woman leaders played prominent roles, the male authours muted their contributions by their way they wrote their stories" ${ }^{\prime 60}$.

\section{Kesimpulan}

Saya sebagai perempuan pendeta GKPS bersama para perempuan pemimpin Kristen lainnya akan sering menyampaikan Allah sebagai parsonduk (berkaitan dengan parbulang dan kisah Boru Sibou). Kami akan lebih sering juga membicarakan aspek-aspek feminin Allah serta hasil konstruksi mitos-mitos sebagaimana yang telah dijelaskan, baik melalui penyampaian pemikiran teologis maupun pelayanan praktis seperti dalam doa bersama, lagu-lagu nyanyian, khotbah, katekisasi, ibadah kategorial, ibadah rumah tangga, dan pelayanan sosial di GKPS dan masyarakat Simalungun pada umumnya. Sebagai perempuan pemimpin, saya percaya bahwa konstruksi terhadap mitos-mitos budaya dan teologi patriarkat yang telah terbentuk menjadi the collective unsconscious dapat dikikis secara bertahap dan kemudian dimunculkan the new collective unsconscious tentang perempuan pemimpin GKPS dan masyarakat Simalungun. Hal tersebut supaya perempuan pemimpin GKPS dapat layak disetarakan dengan para pemimpin laki-laki GKPS. Inilah perjuangan yang masih terus berlangsung yaitu perjuangan para perempuan GKPS untuk menyatakan pengalaman baru mereka melalui keberanian memberi nama terhadap diri mereka dan dunia secara baru.

\section{Kepustakaan}

Agustine. "The Literal Meaning of Genesis", ed. J.H. Taylor in Ancient Christian Writers, vols. 41-42. New York: Newmann Press, 1982.

${ }^{60}$ Karen Jo Torjesen, When Women were Priest: Women's Leadership in the Early Church and the Scandal of their subordination in the Rise of Christianity. (New York: Harper SanFransisco, 1995): 10. 
The City of God, trans. Marcus Dods. New York: Western Library, 1950.

Arnold, Bill T. Genesis. United State of America: Cambridge University Press, 2009.

Christ, Carol P, \& Plaskow, Judith (ed). "Introduction: Womanspirit", dalam Woman Spirit Rising: A Feminist Reader in Religion. San Fransisco: Harper Collins Publishers, 1998.

Daly, Mary. Beyond God the Father: Toward a Philosophy of Women's liberation. Boston: Beacon Press, 1973.

End, Van den. Tafsiran Alkitab Surat Roma. Jakarta: BPK Gunung Mulia, 1995.

Fiorenza, Elisabeth Schüssler. But She Said: Feminist Practices of Biblical Interpretation. Boston: Beacon Press, 1992.

Untuk Mengenang Perempuan Itu: Rekonstruksi Feminis tentang Asal Usul Kekristenan. Jakarta: BPK Gunung Mulia, 1997.

Hyde, Janet Shibley. Half The Human Experience: The Psychology of Women, 3rd ed. Lexchussetington, Massachusetts: D.C. Heath and Company, 1985.

Japinga, Lynn. Feminism and Christianity: An Essential Guide. Nashville: Abingdon Press, 1999.

Kassian, Mary A. The Feminist Gospel. Wheaton, Illionis: Crossway Books, 1992.

Kuntjara, Esther. Jender, Bahasa, dan kekuasaan, edisi revisi. Jakarta: Libri, 2012.

McCall, Robin C. "Most Beautiful Among Women: Feminist/Womanist Contributions to Reading the Song of Songs". Dalam Review and Exposito no. 105, (2008).

McGrath, Alister E. Christian Theology: An Introduction, 2nd ed. Cambridge, Massachusetts: Blackwell Publishers, 1997.

Mollenkott, Virginia Ramey. The Divine Feminine: The Biblical Imagery of God as Female. New York: Cross Road, 1987.

Moltmann, Jurgen. "The Motherly Father: Is Trinitarian Patripassianism Replacing Theological Patriarchalism", dalam Metz J.B., Schillebeeckx, E., and Lefebure, M. eds. God as Father? Edinburgh: T\&T Clark; New York: Seabury Press, 1981.

Ruether, Rosemary Radford. Sexism and God-Talk: Toward a Feminist Theology. Boston: Beacon Press, 1993.

. Introductions in Feminist Theology, ed. Mary Grey dan Lisa Isherwood dkk. England: Sheffield Academic Press, 1998.

Minneapolis: Fortress Press, 2012.

Savitri, Niken. "Feminist Legal Theory Dalam Teori Hukum", di dalam Perempuan dan Hukum: Мепијu Hukum yang Berperspektif Kesetaraan dan Keadilan, edisi kedua ed. Sulistyowati Irianto. Jakarta: Yayasan Obor Indonesia, 2006.

Tillich, Paul. Systematic Theology III. Chicago: University of Chicago Press, 1963.

Torjesen, Karen Jo. When Women were Priest: Women's Leadership in the Early Church and the Scandal of their subordination in the Rise of Christianity. New York: HarperSan Fransisco, 1995. 
Torre, A. De La. Belief A Theological Commentary on The Bible: Genesis. Louisville: Westminister John Knox Press, 2011.

Tucker, Ruth A. \& Liefield, Walter L. Daughter of the Church. Grand Rapids: Zondervan Publishing House, 1987. 